\title{
LAS CREENCIAS INVOLUNTARIAS EN SEXTO EMPÍRICO Y HUME*
}

\section{Lisandro Aguirre **}

"Nosotros no echamos abajo las cosas que, según una imagen sensible y sin mediar nuestra voluntad, nos inducen al asentimiento...

Y eso precisamente son los fenómenos". (Sexto Empírico, Hipotiposis Pirrónicas, I, X, 19)

"Las únicas existencias de que estamos ciertos son las percepciones, que, al sernos inmediata y conscientemente manifiestas, exigen nuestro más riguroso asentimiento y son el fundamento

primero de todas nuestras conclusiones". (Hume, David, Tratado de la naturaleza bumana, I, IV, 2 ).

\section{Introducción}

Con el afán de refutar la crítica incorrecta de que los "escépticos invalidan los fenómenos", Sexto Empírico arguye que el "criterio de la orientación escéptica es el fenómeno, llamando implícitamente así a la representación mental"1. Unos dieciséis siglos más tarde, Hume, por su parte, para evitar la caída en una actitud que denomina "pirrónica", se aferra a lo fenoménico, que en su léxico aparece bajo la forma de términos tales como 'percepciones' (perceptions), 'naturaleza' (nature), 'pasiones' (passions), 'creencias' (beliefs), etc. Como dice en la Investigación sobre el conocimiento bumano,

* Este artículo constituye una ampliación modificada de la ponencia leída en las IV Jornadas de Filosofía Teóricas de la Univ. Nac. de Córdoba, mayo de 2007, referidas al tema "Conceptos, creencias y racionalidad". El título de aquel trabajo fue: "La creencia natural en Hume y su cercanía al asentimiento involuntario en Sexto Empírico".

** Profesor en Filosofía y abogado. Doctorando en Filosofía por la Universidad Nacional de Córdoba. Forma parte de la Cátedra de Filosofía Moderna de la Universidad Nacional del Litoral. E-mail: lisandropedroaguirre@gmail.com.

1 Sexto Empírico, Esbozos Pirrónicos, trad. Antonio Gallego Cao y Teresa Muñoz Diego, Madrid, Editoral Gredos, I, XI, 22, 1993. 
cuando está rebatiendo la postura de los pirrónicos, "la naturaleza es siempre demasiado fuerte para la teoría" (Nature is always too strong for principle $)^{2}$.

El objetivo de este trabajo es mostrar cómo ambas posturas, el escepticismo antiguo de Pirrón y el escepticismo moderno de Hume, pueden llegar a converger en una posición bastante similar. Ambas actitudes teóricas y a la vez prácticas consideran que es lícito dar "asentimiento" (si bien Hume utilizará en ocasiones las palabras 'asentimiento', 'juicio' y otras similares, dándoles sentidos distintos a los de Sexto) a aquello que se presenta al hombre de modo inevitable e independientemente de nuestra voluntad: los fenómenos. Por las dos citas del epígrafe, sabemos que tanto para Sexto como para Hume hay algo, independientemente del nombre que le demos ('phainómenon', 'perceptions'), que nos induce o nos exige "asentimiento", término fundamental que parece indicar un concepto común al escepticismo antiguo y al pensamiento de Hume. ¿Será entonces legítimo o justificado seguir apoyando el juicio de la historia que calificó en un principio a Hume de "empirista" o posteriormente de "naturalista"? ¿No sería más exacto rastrear cierto pirronismo, aunque sea inconsciente, en las ideas del escocés antes que un componente auténticamente empirista o bien naturalista?

\section{Los significados de 'juicio' y 'creencia'}

En un trabajo reciente, Michael Frede pone de relieve con cierta solidez la idea de que el escéptico no renuncia a tener creencias o, al menos,

${ }^{2}$ Hume, David, Enquiries concerning Human Understanding and concerning the Principles of Morals, edited by L. A. Selby Bigge, third edition, with text revised and notes by P. H. Nidditch, Oxford, Clarendon Press, 1975, p. 160. Hay traducción al castellano: Hume, David: Investigación sobre el conocimiento bumano, traducción, prólogo y notas de Jaime de Salas Ortueta, Barcelona, Alianza, 1992, p. 160. En adelante nos referiremos a esta obra con la sigla E.H.U.; asimismo, citaremos las páginas de la primera obra anteponiendo la sigla S.B. para indicar las páginas de la edición de Selby-Bigge y J.S.O. para indicar las páginas de la edición castellana de Jaime de Salas Ortueta. 
puede tenerlas sin infringir por ello la epoche 3 . Este autor se opone de este modo a la interpretación tradicional del escepticismo pirrónico, según la cual el escéptico suspende el juicio y, con esta suspensión, cualquier tipo de creencia ${ }^{4}$. Frede considera, en cambio, que el escéptico siempre cree o piensa algo y tal cosa es perfectamente compatible con su escepticismo ${ }^{5}$. Para Sexto, según Frede, un pirrónico serio puede tener creencias. El gran descubrimiento del escéptico no es el hecho de que sea perfectamente posible vivir sin creencias sino la equipolencia o equivalencia de las distintas opiniones sobre algo, lo que sí conduce a la epoche ${ }^{5}$. El escepticismo antiguo es, por tanto, esencialmente una reacción contra el dogmatismo, contra el intento de "superar la línea" de los fenómenos con la ayuda de la razón, y alcanzar la verdadera realidad, disolviéndose así las contradicciones aparentes o reales entre aquellos ${ }^{7}$. En verdad, la distinción entre apariencia y realidad es un supuesto dogmático que no acepta el escéptico, pues para él nada quita la posibilidad de que, en realidad, las cosas sean exactamente como parecen ${ }^{8}$.

Por el contrario, Burnyeat, al equiparar 'creencia' con "la aceptación de algo como verdadero", concluye que el principal enemigo del escéptico pirrónico es, justamente, la creencia. El sentido que le da este autor al término 'creencia' equivale al de 'juicio', y como el escéptico se caracteriza

${ }^{3}$ Frede, Michael, “The Sceptic's Belief”, en Frede, Michael y Burnyeat, Myles (eds.), The original sceptics: A Controversy, Indianapolis, Hackett Publishing Co., 1997.

4 Dentro de esta interpretación tradicional o habitual del escepticismo quedaría incluido el mismo Ezequiel de Olaso al afirmar que "el pirrónico no afirma ni niega, ni siquiera probabilísticamente" (Cfr. Cabanchik, Samuel, El revés de la filosofía. Lenguaje y escepticismo, Buenos Aires, Editorial Biblos, 1993, p. 63). Sin embargo, según nos informa Cabanchik, la cita de Olaso en la que se basa para incluirlo dentro de la interpretación habitual corresponde a Escepticismo e ilustración. La crisis pirrónica de Hume a Rousseau, de 1981 y dicha posición sería modificada posteriormente por este autor, acercándose en algunos aspectos a la posición de Frede.

${ }^{5}$ Cfr. Frede, M. op. cit., p. 2.

${ }^{6}$ Cfr. Ibid., pp. 7-8.

${ }^{7}$ Cfr. Ibid., p. 13.

${ }^{8}$ Cfr. Ibid., p. 15. 
precisamente por la epoché, no podrá tener creencias9. Se podría decir que el mismo Hume en el siglo XVIII ya había efectuado una interpretación similar. Según Burnyeat, todo lo que admite el escéptico es una "impresión pasiva" (phantasía) o una "experiencia" (pathos) expresada en una declaración sin pretensiones de verdad. El pirrónico "anuncia su propia experiencia sin creencia, sin aserción sobre cosas externas"10. Por lo tanto, es claro que la opinión de Burnyeat es exactamente opuesta a la de Frede. Mientras éste nos habla de las creencias del escéptico en la medida en que no entiende que tal término sea sinónimo de 'juicio', 'dogma' o 'aserción', Burnyeat piensa que Sexto entendía la vida del escéptico como una vida sin creencias, lo que para este comentarista, al igual que para Hume, es imposible. No es casual que su artículo sobre la imposibilidad de vivir escépticamente comience con el cuestionamiento de Hume a los pirrónicos que aparece en la Sección 12 de la Investigación sobre el conocimiento bumano. En igual sentido que la interpretación de Burnyeat, Jonathan Barnes sostiene que el pirrónico no cree, sino que expresa o confiesa sus estados mentales ${ }^{11}$. Además este autor distingue dos clases de pirronismo: a) el "rústico" que dirige la epoché contra toda cuestión que aparezca; b) el "urbano" (o "caballerezco") que sólo dirige la epoché a cuestiones filosóficas y científicas pero no deja de creer en la mayoría de las cosas que cree la gente común. Si bien reconoce que en los Bosquejos Pirrónicos hay elementos para ambas interpretaciones, Barnes considera que Sexto es un "pirrónico rústico"; esto es, un pirrónico sin ningún tipo de creencia ${ }^{12}$. En cambio, haciendo uso de esta clasificación de Barnes, podríamos decir que Hume encaja perfectamente en la definición de "pirrónico urbano", ya que defiende las creencias comunes.

La cuestión central es entonces determinar qué significado habría que atribuir al término 'creencia', y si es posible identificarlo con algunos de los significados de 'juicio', o bien, con el de 'asentimiento'. No se trata de una mera cuestión morfológica ni semántica. Es mucho más que eso. Nos parece que en la elucidación de esta cuestión podrían resolverse varios

9 Burnyeat, Myles, "Can The Sceptic Live His Scepticism?", en Frede y Burnyeat (Eds.), op. cit., pp. 33-34, 37.

${ }^{10}$ Ibid., p 51.

11 Barnes, Jonathan, "The Beliefs of a Pyrrhonist", en Frede y Burnyeat (Eds.), op. cit., pp. 58-91.

12 Ibid., pp. 61-62. 
puntos oscuros o al menos difusos; por ejemplo, podríamos pensar si el escepticismo antiguo involucra el rechazo de toda creencia o si, por el contrario, permite la posibilidad de sostener creencias. De este modo, podríamos analizar si es realmente correcta la tesis de Hume (sobre todo la expuesta explícitamente en la Sección 12 de la Investigación), según la cual su escepticismo es distinto al pirrónico. Fue él mismo quien se esforzó por hacernos creer en esta distinción. Algunos prestigiosos comentaristas suponen que lo que el mismo filósofo dijo de su filosofía es cierto, no sólo por el hecho de haberlo declarado sino porque también existen ideas o principios de su filosofía que podrían avalar la interpretación académica del pensamiento humeano. Cabanchik establece, apoyándose en un pasaje del clásico libro de Brochard, claras analogías entre Carnéades y Hume ${ }^{13}$. Nosotros, en cambio, basándonos en las opiniones de otros expertos y en las propias, nos atrevemos a dudar de las palabras del filósofo, ya que como él mismo lo declaró en su "Autobiografía" respecto de lo que él consideraba su mejor escrito- el autor "no debe ser juez en este asunto"14. Por consiguiente, nuestro objetivo más importante es tratar de responder del modo más imparcial posible, no desde el léxico humeano, a la pregunta: ¿existe alguna diferencia real entre el pirronismo "urbano" de Hume y el pirronismo "rústico" de Sexto? 15

En cuanto a los escépticos antiguos, Burnyeat resalta una característica esencial que no habría que dejar de tener en cuenta en ningún momento. Tal vez, hasta podría servirnos para establecer un puente de afinidad entre Sexto y Hume. Se trata de la marcada pasividad que caracteriza al escéptico antiguo cuando dice asentir a lo manifiesto. Como se puede apreciar en las palabras del epígrafe, Sexto señala que hay cosas que de modo independiente de nuestra voluntad nos inducen al asentimiento. Esto significa que es posible pensar en un asentimiento involuntario, lo que

${ }^{13}$ Cabanchik, S., op. cit., pp. 88-89.

${ }^{14}$ Hume, D., “Autobiografía”, incluida en Hume, D., Tratado de la naturaleza bumana, edición de Félix Duque, Madrid, Tecnos, 1992, p. 16.

${ }^{15}$ Véase al respecto las ideas de autores clásicos como Brochard, Víctor, Los escépticos griegos [1887], trad. Vicente Quinteros, Buenos Aires, Losada, 2005; y contemporáneos como Olshewsky, Thomas, "The Classical Roots of Hume's Skepticism", Journal of the History of Ideas, Vol. 52, N² (April, 1991), pp. 269-287, y Junqueira Smith, Plínio, O Ceticismo de Hume, Sao Paulo, Loyola, 1995. 
permite establecer una diferencia radical entre cierta clase asentimiento (el involuntario) y el juicio, puesto que en el juicio parece intervenir indefectiblemente la voluntad del sujeto, ya sea positiva como negativamente. Desde la tradición racionalista moderna, que se inicia con Descartes, el error es entendido como algo proveniente de la voluntad, entendida ésta como la facultad de elegir o juzgar que consiste fundamentalmente en afirmar o negar. El error surge - de acuerdo con la cuarta Meditación de Descartes- cuando la voluntad (facultad infinita) afirma lo que el entendimiento humano (facultad finita) no concibe con claridad y distinción. Lo que nos interesa rescatar aquí es el valor que otorga Descartes a la voluntad humana en la formulación de juicios ${ }^{16}$. Escribe Descartes: "indagando cuáles son mis errores (que por sí solos ya arguyen imperfección en $\mathrm{mi}$ ), hallo que dependen del concurso de dos causas, a saber de mi facultad de conocer y de mi facultad de elegir -o sea, mi libre arbitrio-; esto es de mi entendimiento y de mi voluntad. Pues, por medio del solo entendimiento, yo no afirmo ni niego cosa alguna, sino que sólo concibo las ideas de las cosas que puedo afirmar o negar"17. Esta concepción de juicio es lo que acerca notablemente a Sexto y Descartes, pero al mismo tiempo separa a este último de Hume, puesto que Hume concibe al juicio como algo involuntario. En el Tratado, cuando se califica a la opinión escéptica de insincera, Hume escribe: "La naturaleza, por medio de una absoluta e incontrolable necesidad, nos ha determinado a realizar juicios exactamente igual que a respirar y a sentir"18. 'Juicio' es entendido aquí por Hume como un sinónimo de 'creencia'. El filósofo duda de todo, pero cuando sale a la calle, siendo también hombre, no puede dejar de creer

16 Pese a la "Objeción Doceava" que le formula Hobbes a Descartes respecto de la voluntad o libre arbitrio, que es una suposición no probada, y encima una suposición contraria a la opinión de los calvinistas. Cfr. Descartes, René, Meditaciones metafisicas con objeciones y respuestas, traducción de Vidal Peña, Madrid, Alfaguara, 1977. ${ }_{17}^{17}$ Cfr. Ibid., p. 47.

${ }^{18}$ Hume, David (1978): A Treatise of Human Nature, Oxford, ed. L. A. Selby-Bigge, second edition, with text revised by P. H. Nidditch, Oxford, Clarendon Press, 1978, p. 183. Hay traducción al castellano de Félix Duque (1992), Madrid, Tecnos, p. 271. En adelante nos referiremos a esta obra bajo la sigla T.H.N. y citaremos las páginas de esta obra anteponiendo la sigla S.B. para indicar las páginas de la edición de Selby-Bigge y F.D. para indicar las páginas de la edición de Félix Duque. 
(o bien de juzgar, en palabras de Hume) que existen cuerpos, que hay un yo interior, que tal objeto es causa de tal otro, etc. Esto no implica de ningún modo la intervención de la voluntad. Para Hume, la "creencia consiste en alguna sensación o modo peculiar de concepción, imposible de destruir por meras ideas y reflexiones"19. Por eso, "hay que agradecer -dice Hume- a la naturaleza, pues, que rompa a tiempo la fuerza de todos los argumentos escépticos, evitando así que tengan un influjo considerable sobre el entendimiento"20. Asimismo en la Investigación sobre el conocimiento bumano, Hume afirma que "la diferencia entre ficción y creencia residen en algún sentimiento o sensación que se añade a la última, no a la primera, y que no depende de la voluntad ni puede manipularse a placer". E inmediatamente agrega respecto de este peculiar sentimiento llamado 'creencia': "Ha de ser suscitado por la naturaleza como todos los demás sentimientos" 21 .

Este modo de comprender el acto de creer (y en Hume también de juzgar) se corresponde con el sentido que los escépticos le daban al asentimiento involuntario. También Hobbes parece haberlo entendido así: "el saber que una cosa es verdadera, como también el creer en ella, o darle asentimiento, son cosas que no dependen de la voluntad [...]. Es cierto que afirmar o negar, mantener proposiciones o refutarlas, son actos de la voluntad, pero de ahí no se sigue que el consentimiento interior dependa de la voluntad"22.

John Passmore sostiene que Hume da tres definiciones distintas de creencia ${ }^{23}$ : 1) creencia como vivacidad ${ }^{24}$; 2) creencia como idea vivaz asociada a la impresión ${ }^{25}$; 3) creencia causal ${ }^{26}$. Sin embargo, nos parece más plausible la opinión de Plinio Smith ${ }^{27}$, quien concuerda con Barry Stroud ${ }^{28}$ al

\footnotetext{
${ }^{19}$ Cfr. T.H.N., S.B. p. 184, F.D. p. 273.

${ }^{20}$ Cfr. T.H.N., S.B. p. 187, F.D. p. 276.

${ }^{21}$ Cfr. E.H.U., S.B. p. 48, J.S.O. p. 71.

22 Cfr. Hobbes, "Terceras Objeciones" en Descartes, R., op. cit., pp. 155-156.

${ }^{23}$ Cfr. Passmore, John, Hume's Intentions, London, Duckworth, 1980, pp. 99-103.

${ }^{24}$ Cfr. T.H.N., S.B p. 86, F.D. p. 149.

${ }^{25}$ Cfr. T.H.N., S.B p. 96 , F.D. p. 161.

${ }^{26}$ Cfr. T.H.N., S.B p. 101-102, F.D. p. 170; también véase E.H.U. S.B p. 48, J.S.O.

p. $71-72$.

${ }^{27}$ Junqueira Smith, P., op. cit., p. 87.
} 
sostener que no hay dos sentidos diversos en la definición de creencia como lo cree Passmore (uno referido a la mente y otro referido a la idea). En verdad, la creencia no es una característica de la idea, sino sólo un modo de concebir una idea que está exclusivamente en la mente.

Ahora bien, uno podría preguntarse cuáles son las cosas que inducen al escéptico pirrónico a asentir; y por otra parte, si en ese asentimiento es posible, desde una auténtica actitud escéptica, creer en aquello a lo que se asiente involuntariamente.

\section{El "asentimiento involuntario" y la involuntariedad de la creencia}

Esas cosas que nos inducen a asentir son llamadas por Sexto "fenómenos", término que deriva del griego tá phainómena que a su vez proviene del verbo phaino, cuyo significado es, entre otras varias acepciones, 'hacer ver', 'manifestar', 'mostrarse', 'aparecer', 'ser claro', 'aparentar ser'. Por lo dicho, etimológicamente, tá phainómena podría traducirse como 'lo manifiesto', 'lo que aparece', 'lo que se muestra'. Por lo tanto, es preciso indagar qué es lo manifiesto, lo que se muestra o aparece ante el pirrónico. Sexto respondería que entre las cosas que aparecen, tá phainómena, el escéptico incluye tanto objetos de los sentidos como objetos del pensamiento; llega a hablar, incluso, de las cosas que aparecen a la razón (lógos) o al pensamiento (diánoia).

No obstante, lo que importa también discernir es si el escéptico, al tomar como criterio de orientación al fenómeno, cree en él. Partiendo de una definición de creencia dada por Villoro ${ }^{29}$, Cabanchik afirma que en la creencia debe haber algo más que la simple representación del objeto ' $\mathrm{p}$ ' (lo que en este contexto se podría equiparar con fenómeno); es necesario además lo que él denomina una "actitud pro-verdad", la cual debe ser entendida disposicionalmente. "Entonces, creer que $p$ significaría -según Cabanchik- representarse el contenido proposicional expresado por ' $p$ ' $y$ tener la disposición a actuar respecto de 'p' como si fuera verdadera" 30 . Si creer presupone esta disposición de actuar como si lo representado en la

\footnotetext{
${ }^{28}$ Stroud, B., Hume, London, Routledge and Kegan Paul, 1977, p. 114.

${ }^{29}$ Cfr. Villoro, Luis, Creer, saber, conocer, México, Siglo XXI, 1982.

${ }^{30}$ Cabanchik, S., op. cit., p. 65.
} 
creencia es verdadero, será necesario analizar entonces dos cuestiones que para nuestra investigación resultan esenciales: a) la posibilidad de que, a pesar de que en esa disposición o actitud pro-verdad incluida en el creer esa representación se tome como si fuera verdadera, no haya en ella un verdadero juicio, sino un juicio aparente, por así decirlo; b) la posibilidad de que en la creencia (entendida en sentido amplio, de acuerdo al punto de vista de Frede) no esté comprometida la voluntad de quien cree, sino que sea algo más bien pasivo.

Si estas dos cuestiones se resolvieran del siguiente modo: en la creencia no hay un verdadero juicio, sino una mera disposición involuntaria a tomar algo como si fuera verdadero, Sexto y Hume podrían considerarse dos portavoces de una misma filosofía, independientemente de que a la palabra 'juicio' le otorguen sentidos no equivalentes. Pues, a la palabra 'juicio' Sexto la entendió como Descartes con el sentido de "afirmación o negación voluntaria", en cambio Hume le dio directamente otro sentido, mucho más cercano al significado de asentimiento involuntario, convirtiéndolo así en sinónimo de 'creencia'.

Para resolver la primera de las dos cuestiones cruciales planteadas, habría que detenernos en el como si... Suponemos que no es lo mismo decir: creemos en 'p' que sabemos 'p'; por ejemplo, el que formula una proposición tal como "creo en la inmortalidad del alma" no tiene la misma actitud o intención de quien formula la proposición que dice "sé que el ama es inmortal", a pesar de que el sentido de la mayoría de las palabras pueda ser casi exactamente igual. En la primera proposición se dice "creo", por lo tanto, actúo como si la inmortalidad fuese verdadera pero de hecho no tengo ni demostrado racionalmente ni comprobado bajo forma posible alguna tal aserción. Pero, si yo expreso en la segunda proposición "sé”, el juicio allí formulado tiene otro alcance, puesto que quien lo formula tiene la pretensión de hacer valer tal opinión como si fuera algo demostrado, objetivo, universal, verdadero e irrefutable. De cualquier modo, tal vez podamos conjeturar que en ambos casos las dos personas que expresan esas proposiciones son, de modo diverso, creyentes. Ahora bien, la creencia del que dice "creo" es diferente a la creencia de aquel que afirma con vehemencia (para usar una expresión de Sexto) "sé" que tal cosa es así como dice. Por tanto, el como si del verdadero creyente, que en este ejemplo sería el modelo hipotético del escéptico con creencias propuesto por Frede, es formulado de 
manera consciente. Esto quiere decir que quien declara "creo que tal cosa es p" no hace de tal opinión un juicio verdadero, esto es, un juicio con pretensión de verdad, por el cual se pretenda voluntariamente describir con un alcance universal lo que está más allá de lo que se aparece (lo real). Aparentemente el escéptico está enjuiciando; por eso decimos que en la creencia del escéptico sólo existe un juicio aparente o en apariencia. En cambio, en la creencia del otro personaje, que en este ejemplo representaría al no escéptico, hay algo diferente. Con su afirmación, este personaje, que podríamos concebirlo como el paradigma de un dogmático, por llamarlo como Sexto, formula un verdadero juicio que presupone la distinción entre lo aparente y lo real, creyendo que lo dicho por él en el juicio coincide exactamente con lo real. En esa afirmación, el que formula el juicio no piensa como si esto o aquello fuera real, sino que juzga que es real. El pirrónico no puede, en cambio, hacer esto, debido a la equivalencia de las razones que se hallan en favor de las opiniones contrarias y además porque no distingue entre lo aparente y lo real. Por ello, decide retraerse de la actividad judicativa. Sin embargo, eso no le impide asentir a lo que se le aparece, narrando o siendo un cronista de lo que le ocurre tanto sensorial como racionalmente. $\mathrm{Y}$ ¿por qué no le puede ocurrir a un escéptico creer en la inmortalidad del alma? A pesar de que de antemano sabe que no hay forma de convencer a los otros de esta creencia (y por tanto no le interesa hacerlo), el escéptico emitirá la suya propia a través de proposiciones que en apariencia resulten similares a los juicios sin que por ello viole la epoché. En la narración o comunicación de su creencia, el pirrónico no posee ninguna pretensión de saber.

Ahora bien, tal vez pueda servirnos para esclarecer un poco más este asunto, la distinción que utiliza Frede para introducir un tercer término entre las puras apariencias, llamadas por Olaso "presentaciones", y los dogmas, que comúnmente son entendidos como juicio. Este autor distingue entre la "creencia en sentido amplio" y la "creencia en sentido estrecho". En este último sentido, la creencia es toda afirmación acerca de lo que las cosas realmente son; en cambio, en sentido amplio, 'creencia' consiste en afirmar lo que las cosas son según cierto punto de vista, el de cada persona en determinada circunstancia. Fácilmente, advertiremos que la creencia en sentido estrecho es la clase de creencia que rechaza el escéptico cuando declara "creo que el alma es inmortal" y desde la que enjuicia el dogmático 
cuando dice "sé que el alma es inmortal"; en el primer caso, el escéptico asiente o afirma lo que las cosas son según su punto de vista, pero de ningún modo lo plantea como lo que las cosas son realmente en sí mismas, en cambio el dogmático lo expresa con esta última intención. Por lo tanto, la creencia en sentido amplio no es eliminada por el escéptico a través de la epoché. En la vida práctica, cuando el escéptico sigue la guía del fenómeno, no se limita simplemente a narrar lo que le parece sino que acepta afirmar lo que las cosas son según su punto de vista. Así Frede intenta mostrarnos que el escéptico tiene creencias, y no es un mero cronista imparcial de lo que le ocurre, sino que narra lo que desde su punto de vista cree que son las cosas. Cabanchik sostiene al respecto que, al menos, habría que distinguir las presentaciones con carga epistémica de las presentaciones sin esa carga, y además aclarar que, a pesar de que el escéptico termine -desde esta perspectiva- identificándose con un creyente, esta identificación no es tan perniciosa, ya que "aun en el ámbito de la mera creencia alguna sombra de duda siempre subsiste" 31 . Para este autor un ejemplo ilustrativo de esta creencia escéptica (en sentido amplio), que admitiría incorporar el equipaje de sus dudas, podría ser la siguiente afirmación: "creo que el vino es dulce, pero es posible que en realidad no lo sea". En palabras de Nagel, se trata de una creencia con sabor peculiar que conlleva cierta ironia y resignación $n^{32}$.

Tal vez resulte más arduo resolver la segunda cuestión crucial referida esencialmente a la involuntariedad de la creencia. Como dijimos más arriba, Hume habla del juicio como sinónimo de la creencia y los entiende a ambos como algo que no depende de la voluntad humana. Antes que él, Hobbes expresa algo similar cuando en las "Terceras Objeciones" a Descartes establece una diferencia entre "creer" y "afirmar o negar", ya que la primera acción es involuntaria mientras que las segundas son entendidas como actos voluntarios. Teniendo en cuenta las distinciones sugeridas por Frede entre las apariencias (presentaciones), las afirmaciones acerca de lo que las cosas realmente son (creencia en sentido estrecho) y las afirmaciones sobre lo que las cosas son según cierto punto de vista (creencia en sentido amplio), analizaremos

\footnotetext{
31 Ibid., p. 76.

32 Nagel, Thomas, La muerte en cuestión. Ensayo sobre la vida bumana, México, F.C.E., pp. 45-46; aunque el título original de esta obra es Mortal Questions. Citado en Cabanchik, S., op. cit., p. 77.
} 
el papel que tiene la voluntad en cada de ellas. Esclarecer esta cuestión nos parece sumamente relevante en vistas a los fines propuestos en este trabajo en el que comparamos el escepticismo pirrónico y el escepticismo humeano. Si llegamos a la conclusión de que en el pirronismo puede haber, pese a la epoché, creencias en sentido amplio, como las reconocidas en la filosofía de David Hume, nos restará investigar si esas creencias que sostiene el pirrónico son tan involuntarias como las creencias naturales a la que el filósofo escocés se refiere. De esta manera podremos saber si existe o no una mayor afinidad entre ambas clases de escepticismo.

Es de suyo evidente que las presentaciones son completamente involuntarias. Hay una infinidad de cosas que no dependen de mí para que se me presenten. De alli, el nombre que reciben: presentaciones. Ahora bien, una cosa es decir: "se me presenta ante mi un objeto que parece tener la forma de un libro", y otra es: "creo que tengo frente a mi un libro". En la primera afirmación, la proposición es una suerte de narración o relato que describe un suceso sin pretensión de veracidad alguna; en la segunda proposición, se pone en juego algo más que una mera narración: está la subjetividad de quien dice "creo..."; por lo tanto, el punto de vista subjetivo altera en la creencia (entendida en sentido amplio) la simple crónica o relato de lo que nos sucede para dar lugar así al sujeto que de alguna manera interviene con el fin de dar un cierto parecer a lo que se le presenta. Entonces, nos surgen los siguientes interrogantes: ¿Interviene la voluntad al emitir un 'parecer' de este tipo? ¿Acaso el sujeto modifica a propósito lo que se le presenta a él de determinado modo? ¿En dónde reside la voluntad al emitir aserciones o afirmaciones acerca de lo que las cosas son según nuestro punto de vista?

Pensamos que en esa clase de afirmaciones tales como "creo que a es b" no existe una activa intervención voluntaria del sujeto creyente. A él le ocurre que cree que 'a' es 'b' y que allí, afuera, hay -según su punto de vistaun objeto " $x$ " de tales o cuales características, etc. En contraposición a esto, la actividad judicativa, propiamente dicha, en virtud de la cual uno afirma que tal cosa es en sí misma así y no de otra forma, presupone la voluntad de quien juzga, ya que éste pretenderá que lo que él afirma (es decir, lo que le parece) en el juicio tenga una validez objetiva y universal, es decir, sea la reproducción fiel del objeto real que, independientemente de nuestra 
percepción, él supone o cree de manera voluntaria que se le presenta en forma pura o neutral y que, por ello, debe valer para todas las demás personas que estarán constreñidas a aceptar ese punto de vista como el único posible. Cabe aclarar que el sentido que Hume le da al término juicio es otro.

Por consiguiente, en las afirmaciones acerca de lo que las cosas realmente son (creencia en sentido estrecho), hay voluntad manifiesta de quien las efectúa. Por otra parte, en las afirmaciones sobre lo que las cosas son según cierto punto de vista (creencia en sentido amplio) no opera ni directa ni indirectamente la voluntad, ya que no hay intención de que esa proposición, que expresa la creencia en alguna cosa o representación, tenga alguna un valor objetivo ni tampoco un alcance universal. En las afirmaciones de la creencia en sentido estricto, actúa la voluntad del sujeto al pretender que su punto de vista se universalice en razón de que reproduce o al menos expresa lo más fielmente posible la realidad tal como es en sí misma.

\section{Conclusiones}

Por todo lo desarrollado, y entendiendo fundamentalmente que los pirrónicos pueden tener creencias en sentido amplio y que ellas pueden ser consideradas como asentimiento involuntario, la mayor afinidad entre el pirronismo y el pensamiento humeano salta a la vista, resultando así bastante clara o, al menos, para nosotros, creíble.

Sin embargo, a pesar de que sea plausible la afinidad existente entre una y otra clase de escepticismo en relación con la creencia, entendida ésta en el sentido mencionado, cabe preguntarse si no hay algo que los distinga. Pues vemos que en el pensamiento de Hume el contenido de las creencias naturales parecen ser el mismo para todos los hombres; en cambio, para Sexto, tomar el fenómeno como criterio de orientación no implica dar un contenido preciso y único a las creencias que nos permiten cubrir las exigencias vitales. Es decir, recordando el ejemplo del Resumen y la primera Investigación sobre el movimiento de la primera bola de billar que, al chocar con una segunda bola que permanecía en reposo, se convierte en causa del movimiento de ésta, no podemos dejar de pensar sin caer en incoherencias que Hume supone que todos los hombres ("normales", podríamos decir) 
asociarán sus impresiones e ideas causalmente del mismo modo, y que por lo tanto, tendrán la misma creencia en la regularidad y uniformidad de la naturaleza que se basará en la suposición fundamental de que el futuro se asemeja al pasado. $Y$ esto se debe al hecho de que la creencia natural en la causalidad consiste en un sentimiento involuntario que tiene en toda alma humana una influencia mucho más fuerte que una fantasía o mera concepción. Lo mismo ocurre respecto de la creencia en la existencia continua e independiente de los cuerpos.

Por lo tanto, si bien Sexto recomienda atender a los fenómenos sin dogmatismos de acuerdo a cuatro pautas o reglas distintas ${ }^{33}$, consideramos que en su propuesta hay una libertad o flexibilidad que en Hume no existe, al menos, con respecto a los contenidos de las creencias humanas. Como ilustrado que es, Hume sigue pensando desde "un punto de vista universal" en la naturaleza humana, suponiendo que todos los hombres tienen las mismas creencias vitales o animales, las cuales, al ser instintivas, son indestructibles e inmodificables para la razón, gracias a lo cual nos liberamos por suerte de caer en la melancolía escéptica. Sexto, por su parte, no va tan lejos; su falta de afán por universalizar lo ayuda a no transgredir su epoché. En este sentido, como así también en otros aspectos importantes, por ejemplo si tenemos en cuenta la melancolía pensante del filósofo escéptico, Hume no parece ser tan fiel a su pirronismo inconsciente. Quizá sean éstas algunas de las aristas o características de la filosofía humeana que separan al filósofo de Escocia de una identificación total con los pirrónicos.

De cualquier modo independientemente de estas diferencias, no pensamos que, por dar un contenido único u homogéneo, aunque no necesario, a las creencias de los hombres, Hume se convierta en un académico probabilista que necesite morigerar el escepticismo "excesivo" en vistas a la necesidad práctica de vivir. En tal sentido, no compartimos la tesis de Olaso expuesta en aquel artículo del año 1977, según la cual "la de Hume fue una crisis escéptica que no concluyó a la manera pirrónica sino académica" 34 . La razón por la que no coincidimos con esta tesis se debe

${ }^{33} \mathrm{Cfr}$. Sexto Empírico, op. cit., I, XI, 23-24.

${ }^{34}$ Olaso, Ezequiel de (1977): "La crisis pirrónica de Hume", Revista Latinoamericana de Filosofia, Vol. III, N² 2, julio, p. 142. 
fundamentalmente al hecho de que los pirrónicos pueden tener creencias involuntarias.

\title{
Resumen
}

El objeto de estudio de este trabajo es la creencia. Nuestro objetivo es mostrar cómo a través de ese concepto el escepticismo moderno de Hume y el antiguo de Pirrón pueden llegar a converger en una posición bastante similar. Ambas actitudes teóricas y a la vez prácticas consideran que es lícito dar "asentimiento a aquello que se presenta al hombre de modo inevitable e independientemente de nuestra voluntad. Sabemos que tanto para Sexto como para Hume hay algo, independientemente del nombre que le demos ("phainómenon", "perceptions"), que nos "induce" o nos "exige" asentimiento, término fundamental que parece indicar un concepto común al escepticismo antiguo y al pensamiento de Hume. ¿Será entonces legítimo o justificado seguir apoyando el juicio de la historia que calificó en un principio a Hume de "empirista" o posteriormente de "naturalista"? ¿No será más exacto rastrear cierto pirronismo, aunque sea inconsciente, en las ideas del escocés? Nuestra respuesta parte de la interpretación no tradicional de Michael Frede que fundamentó con cierta solidez la idea de que el escéptico no renuncia a tener creencias o, al menos, puede tenerlas sin infringir con ello la epoché. La cuestión central será entonces determinar qué significado habría que atribuir al término "creencia".

Palabras clave: "Hume”, "Sexto", “creencia”, "asentimiento", “epoché”.

\begin{abstract}
The object of study in this paper is belief. Our aim is to show how, through this concept, Hume's modern and Pirro's ancient scepticism may converge into a fairly similar position. Both the theoretical and at the same time practical attitudes consider it licit to "assent to what presents itself to man in an unavoidable way and independently from our will". As we now, there is for Sixtus as well as for Hume something, regardless of the name we give it ("phainómenon", "perceptions"), which "induces" us to or "demands" assent from us, [the latter being] a fundamental term which seems to indicate a concept common to both, ancient scepticism and Hume's thought. Would it then be legitimate or justified to keep giving our support to that statement of history that called Hume first an "empiricist" and afterwards a "naturalist"? Would it not be more accurate to trace some pirronism, even unconscious, in the Scot's ideas? Our answer starts off from Michael Frede's non-
\end{abstract}


traditional interpretation, who somewhat firmly set up the idea that the sceptical resign having beliefs, or at least, can have them without by it trespassing the epoché. The central issue will then be to determine which meaning should be attributed to the term "belief".

Key words: "Hume”, “Sixtus", "Belief”, “Assent", “Epoché”. 